\section{ELECTRODE PROCESSES}

$\mathrm{O}$ April 9 and 10 a discussion on "Electrode Processes" arranged by the Faraday Society was held at Manchester. The meeting was attended by nearly two hundred people, including several distinguished overseas visitors.

Faraday Society discussions have often marked an important stage in the development of branches of physical chemistry, and it was at a very timely moment in the development of the subject of electrode processes for such a discussion to take place. It seems to be probable that the most important advance in experimental physical chemistry in the next decade will lie in the application to the science of the techniques of electronic engineering, developed particularly during the War, and the field of electrode processes may be one which will yield readily to attack by the new weapons ; in fact, a most promising start has already been made. For this reason, a review of the subject at this stage will undoubtedly give great impetus to development along the more important lines.

Altogether, forty papers were presented at the meeting, and they were discussed in groups under the headings "General", "Hydrogen Overvoltage", "Deposition of Metals", "Oxygen Overvoltage" and "General Anodic Processes and Cell Reactions". An introduction to the whole discussion was given by Prof. W. F. K. Wynne-Jones (Dundee), and the various sections were introduced by Prof. WynneJones, Dr. A. Hickling (Liverpool) and A. W. Hothersall (Woolwich). The president, Prof. W. E. Garner (Bristol), was in the chair throughout the meeting.

The subject of hydrogen overvoltage was taken first, and at this stage Prof. A. L. Ferguson (Ann Arbor) directed attention in his paper to the many unsolved fundamental problems associated with the interface between electrode and electrolyte, and to the difficulties in interpreting data obtained by different methods.

A communication by Prof. A. Frumkin (Moscow) discussed the mechanism of hydrogen discharge on the basis of extensive experimental work. The data are interpreted as proving that the discharge of hydrogen ions is the slowest stage in the evolution of hydrogen from acid solutions on mercury, but that subsequent stages, for example, the combination of hydrogen atoms to form molecules, may assume importance with low overvoltage cathodes. The slow-discharge theory was the basis of a theoretical contribution by Dr. J. Weiss (Newcastle-on-Tyne), in which the discharge was considered as the transfer of a proton from the hydrated to the surface-adsorbed state. In a lively discussion the slow-discharge theory was strongly criticized by some speakers, one of the points raised being the apparent absence of a satisfactory relation between the work function of the metal and the value of the overvoltage. The chief alternative theory is the slow combination of hydrogen atoms at the cathode. It was regrettable that Prof. Frumkin was unable to be present in order to contribute to the discussion on this controversial issue. Prof. Garner suggested that a compromise between the two theories would probably be more satisfactory than either of them taken by itself.

J. N. Agar (Cambridge) suggested an analysis of overvoltage data in the manner adopted for rate constants, deriving a 'heat of activation' and an 'entropy of activation', as an examination of these parameters might throw some light on the possible discharge mechanism.

Dr. F. P. Bowden (Cambridge) and K. E. W. Grew (Cambridge) presented data on overpotential measurements at very low current densities on mercury which demonstrate that Tafel's equation, whatever its general validity, is in any event closely obeyed by mercury cathodes over the current density range $10^{-10}-10^{-2} \mathrm{amp} . / \mathrm{cm}^{2}$. The same authors re-investigated the capacity of the double layer on mercury in sulphuric acid solution by the charging-time method. Their value $\left(20 \mu \mathrm{f} . / \mathrm{cm}^{2}{ }^{2}\right)$ is in close agreement with measurements by different procedures, but considerably higher than previous values obtained by the same method. It was pointed out in the discussion that, in spite of the agreement between different determinations, the uncertainty in the value of this quantity is still considerable, for example, a value of $12 \mu \mathrm{f} . / \mathrm{cm}^{2}$ was preferred by Dr. Hickling.

The behaviour of palladium electrodes during the discharge of hydrogen was the subject of a paper by H. P. Stout (Saltcoats). P. M. Bryant (Bristol) and G. E. Coates (Bristol) described an investigation of the polarization of platinized platinum electrodes, where an ageing effect of the electrodes was discovered. Periodic changes in the behaviour of anodically polarized platinum electrodes were discussed by Dr. J. A. V. Butler (London) and G. Armstrong.

In the group of "General" papers the subject of diffusion at the electrodes, of importance in the theory of concentration polarization, was treated mathematically by J. N. Agar and by B. Levich (Moscow). The kinetics of rapid electrode reactions have been studied experimentally by J. E. B. Randles (Birmingham), the analysis of the results leading to values for rate constants of electrode reactions.

In an important theoretical contribution, T. B. Grimley (Bristol) and Prof. N. F. Mott (Bristol) calculated from first principles the potential difference at the interface between a solid and an ionic solution, the example chosen being that of the silver silver bromide electrode.

There were several papers on the cathodic deposition of metals. The relation between the structure of the deposit and the conditions of deposition was examined by electron diffraction experiments by Prof. G. I. Finch (London), H. Wilman (London) and L. Yang (London). Two communications by T. P. Hoar and J. N. Agar dealt with the theoretical analysis of electrical conditions in plating baths. Polarization in the electrodeposition of metals was discussed by G. E. Gardam (London), who showed that the physical form of the cathode metal deposit may influence the polarization, the cause being the difficulties of disposing of the new atoms in the grain lattice.

The mechanism of eathodic metal deposition was investigated by Prof. J. Heyrovsky (Prague), using a new modification of the polarographic technique by which electrodeposition involving an irreversible discharge may be recognized. The results show that all one-electron discharges are reversible, but that most processes with more than one electron transfer are irreversible; and it is deduced that the electrons are transferred successively.

The first paper on the subject of anode processes was contributed by Dr. A. Hickling, who directed attention to anomalies observed in some anodic reactions; for example, the Kolbe reaction, where processes occur at a high positive potential in pre- 
ference to other possible reactions requiring a lower potential. There was considerable discussion on this, the question being whether the phenomenon could be explained by some specific adsorption mechanism, or whether a more fundamental electrochemical problem was raised by it.

A number of contributions dealt with determinations of oxygen overvoltage. A considerable degree of reproducibility has been achieved in some of the studies $( \pm 0.01$ to $\pm 0.03 \mathrm{~V}$.$) , but agreement between$ different laboratories is not yet satisfactory. It was urged earlier in the discussion by Sir Charles Goodeve that in overvoltage measurements more attention should be given to the influence of the procedure of measurement on the results. The effect on the oxygen overvoltage of electrode material current density and time for aqueous solutions was examined by Dr. A. Hickling and S. Hill, and that of solvent variation (also on hydrogen overvoltage) by Dr. J. O'M. Bockris (London).

The last group of papers was devoted to other anodic processes and cell reactions in general, several communications dealing with anodic polarization of metal electrodes by surface oxides. M. Haïssinsky (Paris) pointed out that hydrogen peroxide oxidations may lead to chemically different products from anodic oxidations, which does not agree with the general theory of intermediate hydrogen peroxide formation in anodic oxidations.

An interesting contribution by Prof. H. J. C. Tendeloo (Wageningen) showed that electrode potentials are not only of applied but also of direct interest to biologists, and presented data about the application of electrochemical theory to calculate the potentials of plant roots.

A brief summary of this kind cannot, of course, lay claim to either completeness or even impartiality in the selesction of the points reported in it; but the complete proceedings of the meeting, including the papers read and remarks made in discussion, will be published in the Transactions of the Faraday Society as Volume $43 \mathrm{~A}$ (1947).

V. GowD

\section{MILK, TINNED FOODS AND BREAD}

\begin{abstract}
A $T$ the Health Congress of the Royal Sanitary Institute recently held at Torquay, Section E (Food and Nutrition) met jointly on June 6 with the Food Group of the Society of Chemical Industry. Three papers were given at this session, each dealing with an important and topical aspect of food in relation to health. Prof. H. D. Kay (president of the Section) directed the attention of the meeting to the slow decline, that began some years before the War and was acutely accentuated during the winter months of the war years, in the compositional quality, and therefore in the nutritional value to the consumer, of market milk. The only reason for the existence of the milk industry is the fact that cows' milk is a valuable human foodstuff. Anything, therefore, causing a decrease in its nutritional value is of major importance not only to the consumer but also to all engaged in the industry, whether producers or distributors.
\end{abstract}

The insidious but now well-established decline which began to declare itself some years before the War is a diminution both in the fat and the non-fatty solids content of milk (when figures are averaged over the year). This amounts to an increase in its water content; but it is not due to adventitious watering-experimental surveys have shown that there are few indeed of the farmers of Great Britain who are guilty of extending the volume of the milk in this way. The main cause of this slow decline is the increased use, in breeding, of what Prof. Kay called 'watery' bulls, that is, bulls selected merely on account of the high milk yields of their female relatives, without regard for the quality of the milk. 'Watery' bulls of both the Friesian and the Shorthorn breeds are involved; the rapid in. crease in recent years in the number of relatively poor-quality Friesian bulls is well known.

As regards the acute fall in non-fatty solids to well below the 'legal' presumptive limit of 8.5 per cent, a fall which occurred during the late winter months (January to April) in very many herds during the War years and since, and which reached in April 1947 , in some districts, the lowest figures yet recorded, it has been conclusively demonstrated by experiments at the National Institute for Research in Dairying during the past two years that the main cause is a deficiency of winter feeding-stuffs. It is in the valuable proteins of the milk that this compositional defect is most apparent, and not in the fatty portion. An unexpected finding is that shortage of energy (calories or 'starch equivalent') in the cows' diet is more serious in its effects in diminishing the milk protein than is shortage of protein, provided the diet contains sufficient energy. The level of non-fatty solids in the milk returns to normal, or even goes above normal, within a few days of the cows going out to grass in the spring.

Prof. Kay suggested that the quickest and most satisfactory way of reversing the slow decline in average milk quality would be to pay milk producers on the basis of compositional quality and not, as at present, merely on volume. The suggested method of payment, which is already applied in several countries abroad and presents no insuperable difficulties, would reimburse the dairy farmer for making those changes in breeding and management of his herd which would, if persisted in over a few years, achieve again the higher milk quality so desirable from the point of view of human nutrition. The acute fall in winter milk quality, which even to-day does not occur in adequately fed, well-managed herds, can only be dealt with by an improvement in the supply of winter feeding-stuffs. Even if more high-energy concentrates can be imported-and Prof. Kay thinks that every endeavour should be made to increase such imports--it will also be necessary to improve the quality and quantity of home-produced fodders for winter consumption, such as high-quality hay, silage made from young grass or from cereal-legume mixtıres, kale, kale silage, dried grass, etc. A great deal can still be done in this direction on a very large number of dairy farms.

Mr. Stewart Swift (Oxford) spoke of the increasing anxiety with which public health and sanitary authorities are viewing the steady decline in milk quality; it concerns them not only from the point of view of human nutrition but also on legal grounds. $\mathrm{He}$ hoped that no time would be lost in applying the lessons derived from the surveys and the experimental work. Principal A. W. Ling (Seale Hayne) mentioned work carried out under his direction in the Bristol Province on the relation between lowquality hay and the decrease in the compositional 